\title{
Genealogía de la mercantilización del patrimonio cultural en el Centro Histórico de Zacatecas
}

\section{Guadalupe Margarita González Hernández*}

Resumen. El proyecto de cuidado y conservación del Centro Histórico de Zacatecas fue constituido en la década de 1980 por un grupo de empresarios inmobiliarios y por el gobierno estatal. El objetivo era, además de proteger los edificios construidos en los siglos XVIII y XIX, aumentar su valor mercantil y crear la estructura económica, a través del turismo, para rentabilizar su mantenimiento y conservación. El proyecto turístico se fundamentó financieramente por el Estado en regeneración de fachadas, creación de eventos y fomento empresarial. Su impacto económico fue débil a causa del lento crecimiento de turistas y de la escasa derrama económica ante las míseras remuneraciones a los trabajadores. Los resultados económicos no provocaron cambios en la política estatal, por el contrario, se intensificaron el despilfarro, el desvío y el derroche de recursos. En tanto, los residentes reaccionaron contra el Estado sin trastocar la renta monopólica que creó la identidad cultural.

Palabras clave: Centro Histórico de Zacatecas, regeneración urbana, estancamiento económico, patrimonio cultural, movimientos ciudadanos.

* Docente investigadora de la Unidad Académica en Estudios del Desarrollo de la Universidad Autónoma de Zacatecas. 


\section{The Roots of the Commodification of Cultural Heritage in the Historic Center of Zacatecas}

Abstract. The project for the preservation and conservation of the Historic Center of Zacatecas was established in the 1980s by a group of real estate entrepreneurs and the state government. The objective, beyond protecting the buildings that were constructed in the XVIII and XIX centuries, was to increase the commercial value and create an economic structure, based on tourism, to fund its maintenance and conservation. The tourism project is financially based on support from the State, in the restoration of building facades, the creation of events and entrepreneurial promotion. Its economic impact was limited due to the slow growth in tourist numbers and the underperforming economy combined with low pay for workers. The economic outcomes did not provoke changes in state policies: on the contrary, it intensified the misuse, diversion and waste of resources. Meanwhile, residents opposed the State but did so without disrupting the monopolistic profitmaking that derives from the exploitation of the Center's cultural identity.

Keywords: Historic Center of Zacatecas, urban regeneration, economic stagnation, cultural heritage, citizen movements. 


\section{Introducción}

El objetivo del presente artículo es demostrar que el proyecto turístico basado en el uso y aprovechamiento del Centro Histórico de Zacatecas (CHZ) entró en una etapa de estancamiento pese a la fuerte inversión realizada por el Estado para impulsarlo como polo de desarrollo. Se planeó desde la década de 1980 por un grupo de empresarios inmobiliarios, a patir de entonces el Estado generó las condiciones para su rentabilización y organismos internacionales, como la Organización de las Naciones Unidas para la Educación y la Cultura (UNESCO, por sus siglas en inglés), lo refrendaron, al nombrarlo Patrimonio Cultural de la Humanidad en 1993.

Se argumenta que el aludido proyecto turístico, fundado en la remodelación, el uso y el aprovechamiento de un conjunto de edificaciones construidas en los periodos colonial y liberal, tuvo fines exclusivos de generar condiciones de rentabilidad económica para los capitales inmobiliarios, comerciales y de prestación de servicios de entretenimiento y ocio. Ello en detrimento de la conservación y el cuidado del patrimonio cultural y del bienestar económico de sus trabajadores, lo que ocasionó estancamiento económico, precarización laboral y molestias entre los ciudadanos. Sin embargo, los movimientos ciudadanos, en lugar de cuestionar esa mercantilización, se diluyen en la esfera política en contra del Estado por ser el intervencionista.

Inicialmente, el proyecto turístico del CHZ se sustentó en renovarlo y crear la infraestructura adecuada para atender a los visitantes. Con el paso del tiempo y ante el lento crecimiento de turistas con poder adquisitivo, los negocios destinados a sus servicios no generaron ganancias y empeoraron las condiciones laborales y salariales de sus trabajadores. El destino 
de las inversiones estatales continuó hacia la regeneración del CHZ, hasta que los ciudadanos se percataron de que únicamente se beneficiaban unos cuantos. La afectación no es sólo un motivo económico sino su legado simbólico e histórico, el patrimonio edificado representa su identidad. El CHZ, por tanto, está inmerso entre el estancamiento económico y las manifestaciones ciudadanas en contra de remozar su patrimonio cultural.

Con el análisis de datos cualitativos y cuantitativos se constata el aporte restringido de la actividad turística en la economía zacatecana, así como los acontecimientos ocurridos por el proyecto de regeneración urbana y las manifestaciones ciudadanas. El trabajo cuenta con cuatro apartados: el primero refiere a un estudio histórico del proceso de regeneración urbana desde 1980, el segundo aborda el comportamiento de la actividad turística en el CHZ, el tercero explica la manera en que han transcurrido las manifestaciones ciudadanas en contra de las regeneraciones urbanas y el cuarto ofrece las conclusiones.

\section{Regeneración urbana en el CHz}

El CHZ ha sufrido procesos de regeneración urbana desde inicios de la década de 1980 y se debió, aparentemente, al abandono físico que vivió desde que fue disputada por las fuerzas federales y revolucionarias a mediados de la década de 1920. A la luz del análisis que ofrece la retrospectiva, la regeneración urbana se concentró en el mejoramiento de la imagen. Se identifican cuatro procesos históricos:

Regeneración urbana originaria (1980-1986). Inicialmente con recursos extraordinarios de la abundancia petrolera y después del presupuesto 
ordinario, el gobierno estatal ejecutó acciones de regeneración urbana sustentadas en el mejoramiento de la imagen, la expulsión de actividades económicas no centrales (comercio y distribución al por mayor) y de pobladores de bajos ingresos (formal, crédito a viviendas de interés social; e informal, invasión de terrenos periféricos para viviendas de autoconstrucción). Se considera originaria puesto que ese proceso de inversión estatal propició las condiciones generales para crear y rentabilizar intereses económicos inmobiliarios y turísticos a largo plazo.

Bajo el comando de una recién creada Junta de Protección y Conservación de Monumentos y Zonas Típicas del Estado de Zacatecas (desde ahora Junta de Monumentos), un grupo de empresarios inmobiliarios locales y el gobierno estatal delinearon los acuerdos de cómo, quien, cuándo y dónde se debe proteger el primer cuadro de la ciudad de Zacatecas. Fue de tal magnitud la regeneración urbana del CHZ, que el recurso destinado representó casi 90 por ciento del presupuesto otorgado a todo el territorio zacatecano durante los primeros cinco años de haberse establecido (1980-1985); el cual se empleó en rehabilitar edificios, calles y espacios públicos con una restaurada imagen que evocaba a un glorioso pero lejano auge colonial (véase gráfica 1). Desde un principio los riesgos de inversión fueron sufragados por el gobierno estatal y, por deducción, por la población residente. La resistencia al despojo y al desplazamiento de actividades económicas y poblaciones fue casi nula, pues la mayor parte de la población vio la regeneración urbana como necesaria y urgente debido al deterioro del CHZ. En ese sentido, poco importó que comerciantes y pobladores de vecindades fueran expulsados con el fin de crear centros comerciales y hoteles para turistas de mayores ingresos. 


\section{Gráfica 1}

Presupuesto estatal: región Zacatecas, CHZ, servicios urbanos y fomento al turismo, 1981-1985 (miles de pesos constantes 2002=100)



Regeneración estancada (1986-1998). Dentro del contexto de una crisis económica nacional en pleno, los recursos y las ideas regeneradoras de la estructura física del CHZ se restringieron al mínimo. En esta etapa sólo se destinaron recursos para mantener y conservar la estructura e imagen del lugar restaurado en el periodo anterior, así como para costear los servicios de consultoría requeridos, con el propósito de que a finales de 1993, bajo el nombre de Centro Histórico de la ciudad de Zacatecas, la UNESCO lo declarara Patrimonio Cultural de la Humanidad. En contrapartida, el gobierno estatal impulsó créditos y apoyos al desarrollo económico dirigidos a empresarios turísticos e inmobiliarios con la intención de establecer empresas de alojamiento temporal, gastronomía y entretenimiento. Paralelamente, creaba espectáculos eventuales como mecanismos de atracción turística. La resistencia social fue menos relevante, este periodo pasó casi inadvertido para la población zacatecana, sumergida en 
crisis económicas que deterioraban su condición laboral y, todavía más, de reproducción social.

Regeneración y despunte económico (1998-2006). Fue el periodo más exitoso gracias a las mayores derramas económicas generadas por el turismo y la industria del entretenimiento. Adicionalmente, se invirtió de nueva cuenta en otra etapa de regeneración urbana caracterizada no sólo por conservar y mejorar la imagen revitalizada desde la década de 1980, sino por agregar nuevos espacios urbanos a la mercantilización de la cultura y el entretenimiento, aunque muchos de ellos ya no conservaron rasgos coloniales. Destaca también la inversión con asociación público-privada (Harvey, 2006; 2011; 2013), donde la institución estatal corría con las mayores inversiones de riesgo y deuda (basada en inversión a infraestructura y equipamiento urbano), y el capital privado se dedicaba a la remodelación inmobiliaria y al fomento turístico para el turista de alto ingreso. Paralelo a la inversión del gobierno estatal, bajo el aval de la declaración de patrimonio mundial por la UNESCO y los proyectos de fomento turístico auspiciados por la Secretaría de Turismo (Sectur), el gobierno federal comenzaría a impulsar el turismo en el lugar; en tanto, el gobierno municipal realizaría sus primeras acciones como emprendedor urbano al mejorar la imagen de espacios públicos de su incumbencia. Aunque el presupuesto destinado para el proyecto de regeneración urbana y revitalización económica del CHZ fue obtenido de diversas fuentes a gran escala, los recursos destinados nunca superaron el de la etapa de regeneración urbana originaria. Si se insiste en que se trata del periodo más destacado en términos económicos es porque logró terminar con la mínima resistencia al proyecto, una vez que se invitó a artistas, académicos y lugareños a participar en eventos de entretenimiento, proyectos de investigación y fomento económico y cultural. 
Regeneración y revitalización económica superflua (2006 a la fecha). Esta etapa comenzó con la declaratoria del gobierno estatal de destinar una partida exclusiva de su presupuesto para el fomento turístico de Zacatecas. Inicialmente era para impulsar a todo el territorio como «polo de desarrollo turístico» (Gobierno del estado de Zacatecas, 2006); no obstante, la realidad es que el CHZ, como casi único destino turístico, ha aumentado su presencia en el presupuesto a lo largo del tiempo. En 2007, recibió 85 por ciento de dicha partida y para 2013 se incrementó a 95 por ciento (Gobierno del estado de Zacatecas, 2007-2013). Ese presupuesto se destinaba a específicos rubros: a) mejoramiento y conservación del patrimonio cultural, b) planeación estratégica, c) fomento turístico. Este último comprende hasta 75 por ciento del recurso, incluye cualquier tipo de derroche (viáticos de funcionarios para promocionar el CHZ por el mundo, o bien a personalidades extranjeras con el objeto de que conozcan el CHZ y luego lo promocionen en sus lugares de origen, pago a artistas de renombre internacional como «artistas ancla» a los festivales temporales organizados).

Paralelamente, comienza una fractura o, por lo menos, diferencias entre empresarios comerciales, inmobiliarios y turísticos con los gobiernos municipal y local, debido al carácter excluyente de sus acciones y privilegios para un reducido grupo (El Diario NTR, 2013; 2014). Sin embargo, dichas diferencias se diluyeron — después reaparecerían — cuando las temporadas altas de flujo turístico y las derramas económicas subsecuentes se presentaron. La razón principal por la que el presupuesto estatal no se ha dedicado a la conservación y al mantenimiento de la infraestructura edificada y su fomento económico han sido las nuevas formas de captación de recursos impulsados por la competitividad. Bajo proyectos de competitividad turística y con el aval de ser patrimonio mundial, los gobiernos 
municipal y estatal han competido por recursos extraordinarios a escalas nacional e internacional. De ahí se han obtenido recursos con el propósito de que, a finales de 2012 y hasta la fecha, diera comienzo la etapa última de regeneración urbana en el CHZ, y de este modo cambiar radicalmente no sólo su fisonomía sino su dinámica social y económica. Situación que ha provocado movimientos ciudadanos en contra de dicho proyecto y a favor de la protección del patrimonio cultural del CHZ. A raíz de convertirlo en polo de desarrollo turístico y destinarle una partida exclusiva, los recursos fluyeron en cantidades insospechadas. Los gastos exorbitantes de la época originaria son nimiedades ante los gastos superfluos de los años recientes, época caracterizada además por presentar derramas y flujos de turistas mediocres (véase gráfica 2); circunstancia que ubica al CHZ en el décimo tercer lugar en el ranking de destinos turísticos de la Sectur desde 2007.

\section{Gráfica 2}

Presupuesto ejercido en el CHZ, 1981-2012

(miles de pesos constantes)

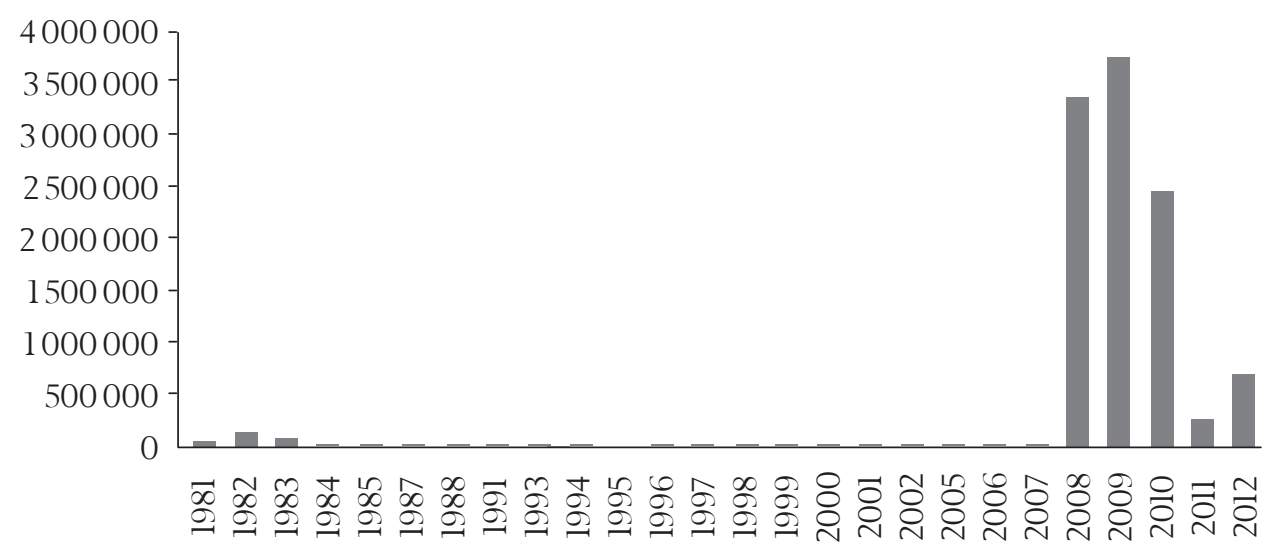

Fuente: Gobierno del estado de Zacatecas (1981-2012), INEGI (2012). 


\section{Composición económica y su impacto (1988-2008)}

Fundado en los fenómenos de reestructuración, suburbanización y revitalización, el CHZ ha perdido importancia económica en las dos últimas décadas. En 1988 contribuía con 18 por ciento del PIB de la ciudad Zacatecas-Guadalupe, mismo que incrementó a 19 por ciento en 1993; pero en 2008 el porcentaje se redujo a 6 por ciento. Ante el desplazamiento de la población hacia la periferia y su cercana localización consecuente de la actividad económica — concretamente en la zona limítrofe entre las ciudades de Guadalupe y Zacatecas_- la decadente participación económica del CHZ también se manifestó en el aporte dentro de la dinámica del empleo. A finales de la década de 1980, el CHZ concentraba 25 por ciento del personal ocupado de toda la CZG; veinte años después sólo concentró 5 por ciento.

La mayor concentración de personal ocupado se verificó en el comercio: en 1988, del total de empleos creados en la actividad terciaria realizada en el CHZ, 60 por ciento se concentró en el comercio, mientras que el turismo y el resto de los servicios acapararon 20 por ciento respectivamente. Para 2008, la situación no cambió mucho: 42 por ciento del empleo se concentró en el comercio, 23 en el turismo y 35 en el resto de los servicios (INEGI, 1989; 1994; 1999; 2004; 2009).

Referente al personal ocupado en establecimientos localizados en el CHZ, su mayor valor lo tuvo en 2003 con 5 mil 307 personas ocupadas. La mayor parte dentro del comercio al por menor desde 1989 y hasta 2003. En 2008, ante la caída de contratación de personal en el comercio, el sector servicios casi lo alcanzó (trescientos empleos menos). En tanto, el sector turístico mantiene un ritmo de crecimiento casi nulo: en treinta años, sólo trescientos empleos adicionales fueron creados (véase gráfica 3). 
Gráfica 3

Personal ocupado por subsector en el CHZ, 1988-2008

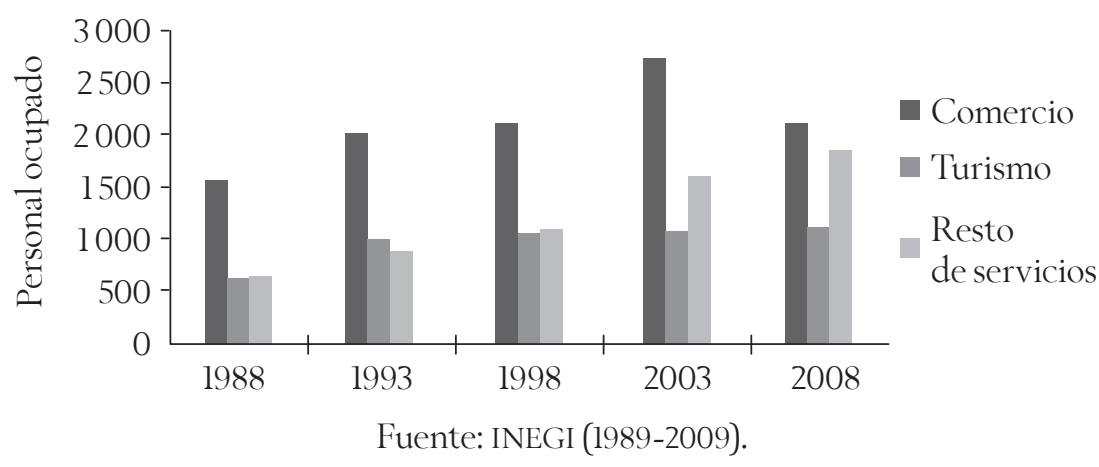

La predominancia del comercio es evidente en la generación de ingresos. Pese a su caída en el número de establecimientos y personal ocupado en 2008, el comercio siguió generando y dominando con proporciones mayores a 72 por ciento del ingreso captado en el CHZ, en contraste con 10 por ciento en promedio del sector turístico durante el periodo (véase gráfica 4).

\section{Gráfica 4}

Ingresos derivados de la actividad por subsector en el CHZ, 1988-2008 (miles de pesos constantes 2002=100)

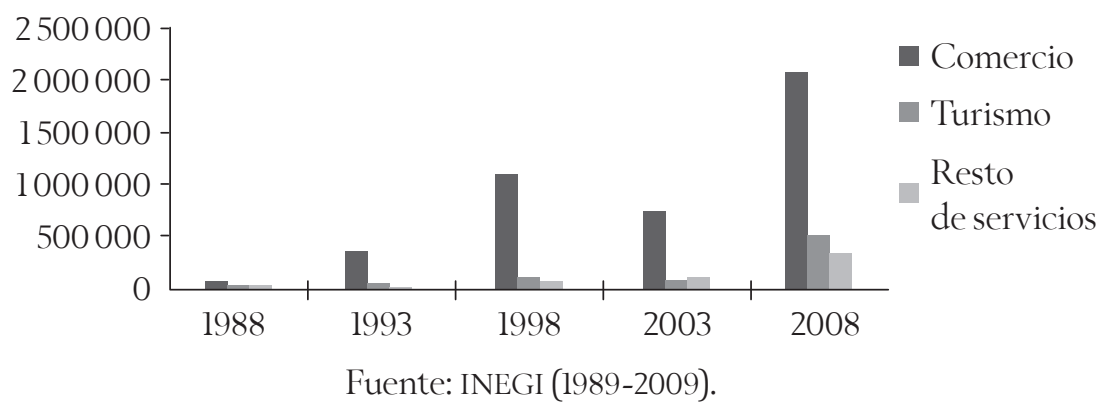


El comportamiento más inestable y a la vez alarmante se relaciona con la proporción de trabajadores que no reciben remuneración. La actividad terciaria, y en especial la de tamaño pequeño, se distingue principalmente por ser de tipo familiar donde los trabajadores no reciben remuneración por sus jornadas laborales, lo cual es muy característico de los negocios comerciales en el CHZ.

La proporción de dichos trabajadores no sólo se ha incrementado con el paso del tiempo en el comercio, sino en el resto de la actividad terciaria del CHZ. La gráfica 5 ofrece un panorama al respecto. Desde 1998, el comercio ha sido el principal generador de trabajadores sin remuneración, los servicios han aumentado su proporción en 480 por ciento y el turismo en 77 por ciento. Esto remite al incremento considerable de negocios estables o no en un lugar fijo, que refieren, en concreto, al autoempleo proporcionado en cualquier tipo de servicio. En el caso del turismo, se manifiesta un incremento de negocios de tamaño pequeño donde los familiares o con relación semejante trabajan sin remuneración; asimismo, a la generación de empleos en la que el propietario del servicio turístico puede contratar personal sin recibir un pago en contrapartida y dependen en particular de ingresos proveídos por los turistas. El caso específico de las propinas es una práctica cotidiana en el turismo que deslinda al empresario turístico de pagar salarios a sus empleados, aunque se beneficie de su trabajo.

El CHZ exhibió un dinamismo económico que parece estar a la baja, sobre todo a finales del periodo 1988-2008. Pese a ello, el comercio representó un generador significativo de ingresos y, por ende, el trabajador del establecimiento comercial fue más productivo que el del sector servicios y turístico. En realidad, el sector turístico durante el periodo en cuestión 
mostró indicadores mediocres en generación de establecimientos, empleos, salarios, valor agregado e ingresos.

\section{Gráfica 5}

Proporción de personal ocupado no remunerado en el total por subsector en el CHZ, 1998-2008

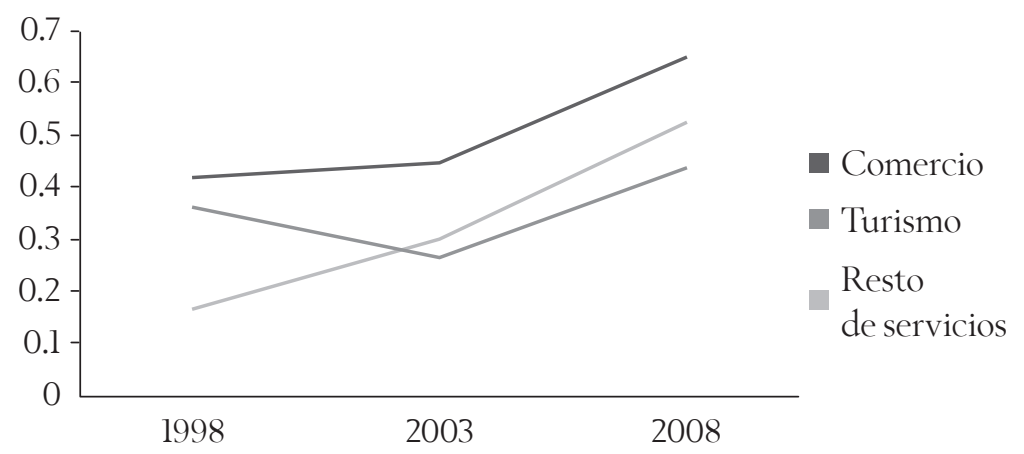

Fuente: INEGI (1999; 2004; 2009).

Los ingresos generados en este rubro a precios constantes se han elevado paulatinamente en el comercio al por menor, mientras que en el comercio al por mayor van en franca retirada; aun así son los establecimientos que venden productos no alimenticios especializados (tiendas de ropa, calzado, regalos, farmacias, etcétera), comercio automotriz (refacciones, llantas, venta de autos) y tiendas departamentales y almacenes, los cuales concentraron el mayor ingreso por trabajador. Esto es, el pequeño comercio tradicional zacatecano tuvo la mayor productividad de sus trabajadores en la obtención de sus ingresos, no obstante a la proliferación de grandes supermercados durante el periodo analizado. En ese caso, a la fecha, fueron los micro y pequeños establecimientos los que mantuvieron el ritmo de crecimiento 
económico de la actividad comercial del CHZ y no las cadenas nacionales de comercialización en términos de ingreso por trabajador.

Referente al sector turístico, un trabajador de los servicios privados de esparcimiento — cine, radio, teatro y televisión — generó, en promedio al año, 2 mil 400 pesos constantes en contrapartida de los trabajadores de servicio de restaurantes, bares y centros nocturnos, quienes apenas generaron 900 pesos constantes al año. Es innegable el fomento económico de este sector en los últimos años al contar con una partida exclusiva en el presupuesto estatal; con todo, no ha aportado mucho al crecimiento económico del CHZ: generación de empleo, remuneración salarial y valor agregado permanecen estancados desde 1998. Ello no impide la concentración de personal en empresas de tamaño mayor al promedio en el casco colonial.

El impulso del turismo, más que crear un impacto positivo y diverso en la estructura económica del CHZ y de las ciudades Zacatecas y Guadalupe, se manifiesta como un generador originario, propiciado por el estado de condiciones de rentabilidad para un grupo social en específico: el capitalista del sector entretenimiento y ocio.

Así, el CHZ, en la etapa comprendida, fue un centro turístico «del montón» con respecto a flujos de turistas según la jerarquización de Sectur. A partir de 1986, tendencialmente ha aumentado su captación de turistas a pesar de las caídas en el primer quinquenio de la década de 1990, en 2002 y 2011. De 139 mil 245 turistas en 1986 pasó a 465 mil 452 en 2012, con un incremento de 334 por ciento (véase gráfica 6). De 1986 a 1999, se verificó un periodo de constante ascenso y con cierta estabilidad en dichos flujos. Este comportamiento fue muy similar al que presenta el país en el mismo periodo, aunque el incremento fue menos pronunciado (322 por ciento). 


\section{Gráfica 6}

Afluencia de turistas en el CHZ, 1986-2012

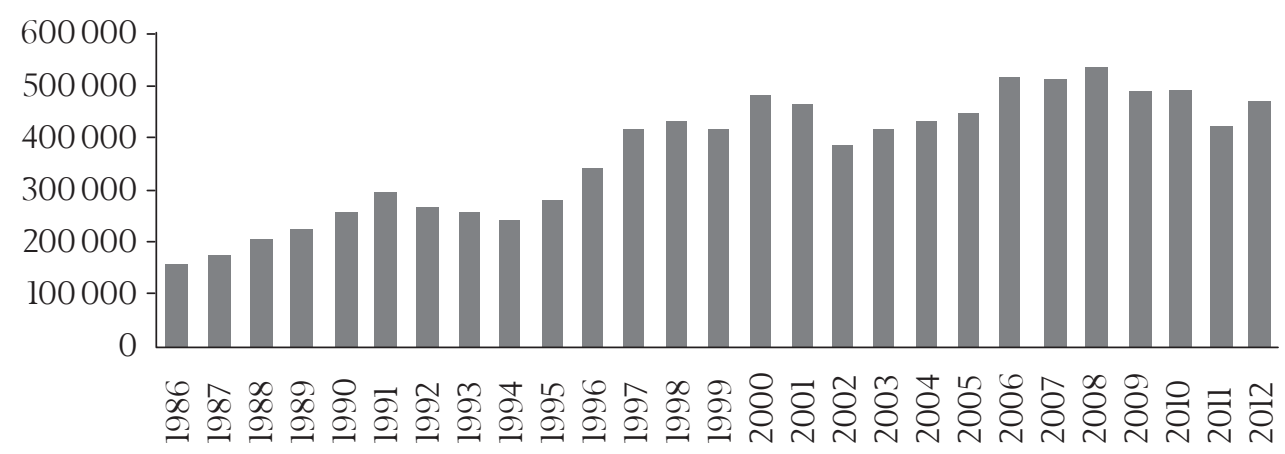

Fuente: Secretaría de Turismo (2012).

Los flujos de turistas llegados al CHZ y su ritmo de crecimiento no sugieren un proyecto turístico con ritmo ascendente relevante. Los montos de turistas revelaron volatibilidad y vulnerabilidad a cualquier tipo de eventos (crisis y desaceleraciones económicas, pandemias de influenza, inseguridad pública) desde el año 2000.

Si se examinara el CHZ desde la perspectiva de la rentabilidad de la actividad turística, no sería muy significativo su escasa relevancia en los ámbitos nacional y mundial, incluso si los flujos de turistas fueran, aunque decrecientes, suficientes para mantener su permanencia como destino turístico. En ese sentido, se obtuvieron los datos sobre la derrama económica recabada por el sector turístico en el CHZ a lo largo de varios años (1988-2011).

La derrama económica a precios constantes de 2002, indicó un comportamiento errático; si bien se registra un incremento en su escala a partir de 1992, no ha sido suficiente para considerar una tendencia ascendente y estable. La vulnerabilidad y la estabilidad visible en el flujo de 
turistas se presentó también en la derrama económica dejada en el CHZ (véase gráfica 7).

\section{Gráfica 7}

Derrama económica por turistas en CHZ, 1988-2011

(miles de pesos constantes 2001=100)

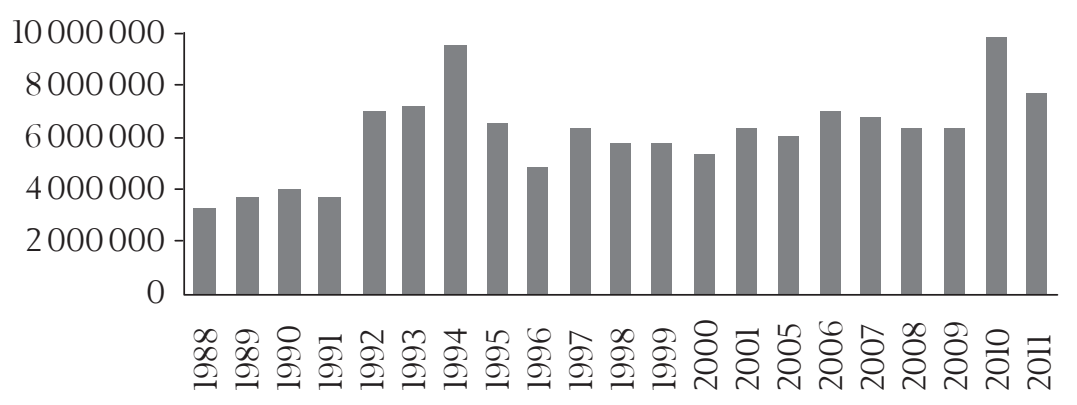

Fuente: Gobierno del estado de Zacatecas (1988-2012).

El gasto promedio por turista (se obtuvo al dividir la derrama económica dejada entre el número de turistas que visitaron el CHZ) es reducido (véase gráfica 8). En 1988, un turista gastó mil 670 pesos promedio durante su estancia; cantidad que se incrementó en el año 1994, a 3 mil 624 pesos y a partir de 1996 y hasta 2009 se mantuvo estable, en promedio mil 200 pesos constantes por estancia, donde mínimamente gastó en alojamiento y alimentación. Sólo en 2010 y 2011 se superó apenas el gasto de 1988 con mil 800 pesos constantes por turista durante su estancia. 
Gráfica 8

Gasto promedio por turista en el CHZ, 1988-2011

(miles de pesos constantes 2002=100)

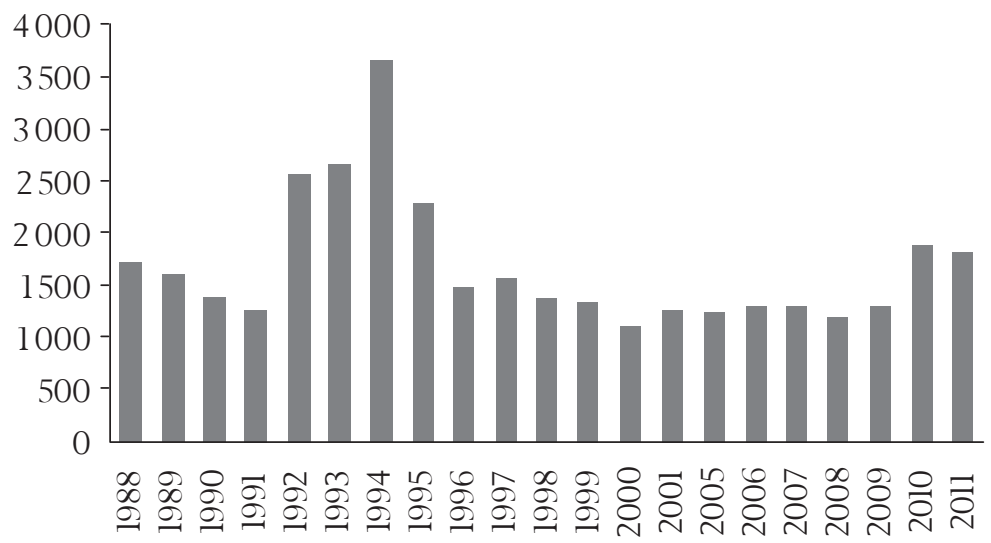

Fuente: Secretaría de Turismo (2012)

y Gobierno del estado de Zacatecas (1988-2012).

Con reservas del caso, producto de la veracidad de los datos vertidos por el Gobierno del estado de Zacatecas (1988-2012) y la Sectur (2012), el turista que visitó el CHZ gastó poco en su estancia, además no existe evidencia o tendencia a que haya un incremento en el periodo analizado o que suceda en los próximos años. El bajo gasto promedio de un turista realizado aludió a una competitividad mediocre del sitio como destino turístico. Su viabilidad como proyecto turístico es reducida. 


\section{Movimientos por la protección del patrimonio cultural del $\mathrm{CHz}$}

Desde 1980 y hasta 2012, la evidencia parecía indicar que la sociedad zacatecana asimiló de manera plausible lo que consideraba bueno, bello y apropiado para el CHZ, según lo dictaba la mercantilización del patrimonio bajo las acciones de las instituciones estatales. Se asumieron principalmente dos posturas:

Pasiva y presencial, al disfrutar de la imagen que proyectan los monumentos y del ocio. Los residentes se clasificaron, por una parte, en aquellos que sólo pasearon y, por otra, en aquellos que accedieron a bienes y servicios producidos por la industria del ocio. Así, estas acciones implicaban un proceso excluyente, elitista o de distinción entre quienes realizaron actividades mercantiles y quienes no lo hicieron.

Asociativa, asociaciones civiles o culturales que crearon una opinión pública sobre cómo veían a la ciudad y cómo desearían que fuera. Al interior de esa corriente surgieron dos posturas aún más radicales: a) un grupo más institucionalizado, aunque muy heterogéneo, que forjó una postura pocas veces crítica y otras más superficial de las acciones estatales urbano-culturales, pero que siempre respetó los principios de fomento al patrimonio colonial y la actividad económica establecida; $b$ ) un grupo menos organizado y más homogéneo, con sentido crítico, involucrado con la cultura popular zacatecana. Si bien se enfoca en la crítica de la política cultural estatal, busca un acceso equitativo a los recursos de la ciudad y evidencia las acciones fácticas mediante el mantenimiento y conservación del patrimonio edificado y cultural inmaterial, ante inexistentes mecanismos de participación ciudadana y de gobernanza. 
En los primeros meses de 2013 comenzaron las remodelaciones y regeneraciones urbanas en la Alameda, la Plaza de Armas, los barrios de San Cayetano y Los Filarmónicos, la Plazuela de García y las avenidas Morelos, Insurgentes y Torreón, ubicados en el CHZ. Aparentemente, dichos proyectos de mejoramiento de imagen en edificios, espacios públicos y calles fueron necesarios. El deterioro que han sufrido edificios, casas y calles debido al tránsito de personas, mercancías y vehículos con el paso del tiempo y la falta de mantenimiento han presionado a las autoridades gubernamentales a regenerarlos.

Estas acciones carecieron de legitimidad ciudadana al implantarse sin analizar las consecuencias económicas, sociales y ambientales. En la fase de planeación, es práctica cotidiana de las instituciones involucradas en la regeneración urbana «consultar» al ciudadano (La Jornada Zacatecas, 2014); sin embargo, los reclamos, las críticas y los impactos negativos suscitados de inmediato, posterior al inicio de las actividades, demostraron ineficacia e ineptitud gubernamental, además evidenciaron que la regeneración urbana llevada en el CHZ tuvo un cariz más de imposición que de discusión e implantación por y para sus ciudadanos.

Aparte de los inconvenientes y los costos que ocasionaron este tipo de remodelaciones a vecinos y a transeúntes durante los años 2013-2016, se desencadenó una serie de violencias que aluden más a la forma en cómo se visualizan, planean e implantan esos proyectos, con impacto a largo plazo en la dinámica urbana zacatecana, que a acciones que permiten el mejoramiento de sus condiciones de vida.

En el presente estudio se exhiben sólo algunas violencias y contradicciones ejercidas por las instituciones estatales en contra de la vida urbana zacatecana. La primera es el tipo de regeneración: planchas con detalles al 
relieve, donde no se distingue frontera entre el espacio público y el privado, ni de peatón y vehículo, con fachadas homogéneas que hacen referencia a un escenario museificado (y por tanto, estático), y que se asocia más con lo que desea contemplar el turista que con lo que desea ver y sentir el zacatecano. Al respecto, ¿dichas regeneraciones urbanas articulan lazos de convivencia entre vecinos y visitantes? La respuesta es obvia si se toma como ejemplo lo que sucedió en la regeneración de la avenida Ramón López Velarde o en la creación de la Plazuela Miguel Auza, lugares que lucen vacíos e impulsan cafeterías al aire libre, pero que rompieron las prácticas cotidianas realizadas ahí.

La segunda se enfoca en la regeneración del patrimonio edificado. En teoría, el patrimonio cultural indica preservar la autenticidad, la identidad y el valor único del patrimonio inmaterial y material asociado al patrimonio urbano-arquitectónico y a la totalidad de relaciones sociohistóricas, económicas, políticas y culturales que le dan sentido a su desarrollo. En la práctica zacatecana, ante la ausencia de un marco legal sólido en términos de aplicación, ejecución y castigo, se han modificado, cambiado o sustituido aspectos esenciales del $\mathrm{CHZ}$ que atentan contra su autenticidad y valor único.

La tercera aborda la revitalización o reactivación económica del Centro Histórico. No existe evidencia de que tales regeneraciones tengan un influjo positivo en su revitalización económica. Quienes justifican estos proyectos desconocen la dinámica económica y urbana del Centro Histórico. Estos proyectos de regeneración urbana intensifican las violencias contra sectores no gratos a la nueva imagen urbana que se pretende crear. Los actos en contra de los comerciantes dedicados a ventas no turísticas (librerías, enseres domésticos, abarrotes, ropa o cosmetología) son un claro ejemplo de violencia institucional en contra de lo que realmente genera 
ingresos, salarios y riqueza; aunado a que no reciben apoyo en ninguna circunstancia, se les niega un espacio para su actividad (El Diario NTR, 2014).

Finalmente, la violencia menos visual y más grave es la de la exclusión y la satanización. Se trata de excluir toda práctica cotidiana, actividad, grupo o individuo que no se adhiera al pensar y actuar de un reducido grupo con poder político-económico, a través de la modificación, en apariencia arquitectónica, de los espacios públicos, quebrantando a la vez la identidad y el sentido de pertenencia. Si existe un mínimo viso de crítica o contrariedad, se le sataniza o se le somete bajo distintos mecanismos. Al final es una exclusión económica y social sin miramientos por los intereses de un grupo hacia los zacatecanos no asociados a convertir en destino turístico museificado a su terruño.

Ante las prácticas de exclusión social e imposición arquitectónica implícitas en el proyecto de regeneración urbana y revitalización económica del CHZ se han manifestado en contra diversos movimientos ciudadanos: a) Vecinos de la Alameda y Pro Alameda reaccionaron ante la primera propuesta de modificar la Alameda a inicios de 2013, después de más de 15 meses, aceptaron el último ofrecimiento; no obstante, al concluir la obra, de nuevo mostraron su inconformidad porque no se respetó el proyecto. b) Vecinos del Centro Histórico y Protectores del Patrimonio Zacatecano no cedieron, para ellos no existió justificación en remodelar la Alameda, la Plaza de Armas, incluso el CHZ, pues eran acciones corruptas que favorecían intereses inmobiliarios y turísticos, así como la apropiación de recursos estatales por particulares constructores bajo el manto de la licitación (Ollanquidia, 2014).

Cuando el gobierno estatal informó de la remodelación de la Alameda a finales de 2012, los vecinos se manifestaron en contra debido a la ausencia de 
socialización del proyecto, en particular a la falta de consulta en cuanto a sus necesidades y a sus preferencias. Como casi siempre sucede, el gobierno estatal (junto con el municipal y el Instituto Nacional de Antropología e Historia, INAH) quiso direccionar a la opinión pública argumentando su disposición para hacer de este proyecto un ejemplo de gobernanza urbana. Fue hasta octubre de 2014 cuando los vecinos de la Alameda autorizaron el proyecto. El gobierno considera que dicha empresa fue exitosa, puesto que se conservó el trazo original de la Alameda en 70 por ciento; complementariamente, las reformas que se hicieron se encaminaron a alejar a las personas indeseables.

A mediados de 2015 volvieron a proclamarse en contra, según sus propias palabras fueron traicionados por el gobierno estatal al no respetar acuerdos en el proyecto de remodelación autorizado. Entre dimes y diretes, la remodelación avanzó poco debido a detenciones tanto por los vecinos como por la incapacidad de la institución estatal en la solución de problemas básicos: drenaje, inundaciones y hundimientos.

En contraposición, el grupo Vecinos del Centro Histórico y Protectores del Patrimonio Zacatecano, con fundamento en un discurso crítico, siempre se opuso al proyecto de remodelación de la Alameda, motivo por el cual fue excluido de seguir participando en las pláticas con las instituciones estatales. El grupo argumentaba que no era necesario cambiar radicalmente la fisonomía del espacio público, en cambio, sí era urgente remozarlo y conservarlo. Ante la exclusión en las pláticas y en los acuerdos con el gobierno estatal, se convocó a una cadena humana que detuviera la acción de manera simbólica. La respuesta ciudadana fue casi nula. Aun así, el grupo consiguió que un notario diera fe de los hechos y presentara un amparo por detención parcial de la obra. Finalmente, el amparo no procedió porque se excedió en el tiempo reglamentario. 
A finales de abril de 2015, la institución estatal dedicada a la obra pública anunció la remodelación de la Plaza de Armas; el grupo Vecinos del Centro Histórico y Protectores del Patrimonio Zacatecano, a través de las redes sociales, convocó a hacer cadenas humanas en contra de esta acción urbanística. A diferencia de lo sucedido en la Alameda, la respuesta ciudadana fue mayor, incluso se mostró solícita a firmar un amparo contra dicha remodelación y un documento para enviarse a la UNESCO. Ante el impacto social de rechazo a esta obra, el gobierno estatal se vio obligado a detenerla alegando que todavía no contaba con los permisos del Comité Nacional Mexicano del Consejo Internacional de Monumentos y Sitios (Icomos, por su acrónimo en inglés) y del INAH. En el caso de Icomos, aseguró no autorizar la obra porque dañaba el patrimonio cultural, algo que ignoraron tanto la institución estatal como el INAH. Las redes sociales fueron la plataforma que posibilitó externar la inconformidad ciudadana, pues los medios de comunicación impresos (excepto El Diario NTR), radiofónicos y electrónicos se mostraron indiferentes.

Posterior a un lapso considerable para aquietar los ánimos, el gobierno estatal reinició las obras de remodelación de la Plaza de Armas a inicios de junio, acción que le permitió al grupo de Vecinos del Centro Histórico y Protectores del Patrimonio Zacatecano presentar dos amparos que tuvieran como fin detener parcial y definitivamente la remodelación de la Plaza de Armas. Aunque los procesos sí procedieron, el juez no ha dado el fallo definitivo por razones que a la fecha se desconocen. Además, este grupo mandó dos expedientes completos de los hechos a la UNESCO, en las sedes de México y de París.

Casi al concluir el año 2015, Vecinos de la Alameda, Pro Alameda, Vecinos del Centro Histórico y otros grupos más (Apazac, Vecinos de la Fernando 
Villalpando y locatarios del Mercado González Ortega), se unieron a través de la Red de Organizaciones Ciudadanas en Defensa del CHZ con el fin de afrontar colectivamente todas las acciones público-privadas en contra del patrimonio. Su primera acción fue oponerse al desalojo de dichos locatarios por parte de la presidencia municipal de Zacatecas, la cual tenía planeado concesionar el mercado a la transnacional Cervecería Modelo por 25 años, para convertirlo en centro cervecero de entretenimiento.

Durante los primeros meses de 2016, gracias a la organización de festivales culturales y manifestaciones en la calle, la Red logró detener el proyecto de concesión a la cervecera, pero fue la coyuntura política la que realmente lo zanjó. Las elecciones a gobernador, presidente municipal y diputados estatales estaban a punto de realizarse en junio de ese mismo año. Esta Red aprovechó el escenario político y ciudadano para movilizar a un candidato independiente para la alcaldía. Los resultados beneficiaron a una candidata del Movimiento Regeneración Nacional (Morena) quien amenazó a los concesionarios cerveceros y a los políticos involucrados de suspender e investigar los mecanismos de apropiación del Mercado González Ortega. Bajo mecanismos legaloides, los partidos principales (PRI y PAN) consideraron ilegales las elecciones y, otra vez, la candidata independiente, apoyada por la Red, comenzó su proceso de campaña. Aunque las segundas elecciones favorecieron al PRI (hubo 70 por ciento de abstencionismo) la candidata de la Red quedó como regidora. A partir de entonces, el movimiento se desenvolvió en la esfera política.

Más allá de la efervescencia inicial y de ser catalizador del hartazgo ciudadano sobre el despilfarro y la voraz mercantilización del patrimonio cultural en los últimos años, este movimiento de protección al patrimonio y respeto a la identidad cultural no ha logrado despertar una 
participación fehaciente y real de los pobladores de la zona metropolitana de Zacatecas. Salvo las actividades de apoyo en firmas y cadenas humanas, el resto de actividades, como la realización de foros de discusión y de difusión de acciones, no han tenido mucha resonancia en la opinión pública ni en los zacatecanos. Los gobiernos estatal y municipal se muestran indiferentes ante estos actos y de manera enfática insisten en remodelar el resto del CHZ.

El movimiento dirigido en un principio por el grupo Vecinos del Centro Histórico y Protectores del Patrimonio Zacatecano (y luego por la Red de Organizaciones Ciudadanas en Defensa del CHZ), si bien reconoce implícitamente que detrás de las remodelaciones se esconde un proceso de mercantilización del patrimonio en aras de auspiciar la acumulación de capital en su sentido más amplio y a escala global (Ríos, 2015 y 2015a), no expone en sus fundamentos de actuación y de pronunciamiento tal fin. Se ampara en el argumento de que el CHZ es un patrimonio cultural de la humanidad, cuyo excepcional valor debe ser preservado para el disfrute de los zacatecanos presentes y futuros.

\section{Conclusiones}

El proyecto de regeneración urbana, impulsado a inicios de la década de 1980, se concibió con el propósito de otorgar valor mercantil a las edificaciones legadas desde los periodos colonial y liberal por parte de sus dueños, los empresarios inmobiliarios y los prestadores de servicios. En ese sentido, fue necesario que el Estado generara las condiciones para su rentabilización a través de invertir en el remozamiento del espacio urbano. 
La baja demanda del lugar tanto de turistas como de visitantes ha puesto en entredicho su vialidad; aunado a que la remuneración del trabajador turístico es el eslabón más débil. Todavía más: con el objetivo de prolongar su declive económico, el Estado le apuesta a la valorización del CHZ provocando discordias y disputas entre los ciudadanos. Pese a que el movimiento ciudadano - a favor de la protección del patrimonio cultural suscitado en el CHZ - cuestiona la mercantilización de lo cultural proveniente de la acumulación de capital, se debate en la esfera política ante la intervención del Estado como gestor del capital y la necesidad de preservar su identidad e idiosincrasia.

Estas prácticas no son neutrales, son parte de la apertura de nuevos espacios de inversión centrados en nuevas temáticas, como la cultura (asociada al turismo), misma que, al igual que cualquier espacio de inversión, se ha abierto a la mercantilización a través de su fomento y difusión, además es un espacio de inversión poco cuestionado. Los instrumentos y los mecanismos pueden ser distintos, pero los fines se asocian más a la acumulación de capital en su fase ampliada y menos por el cuidado y el mantenimiento de la identidad y el patrimonio cultural de un pueblo.

En adición, este tipo de estrategias aumenta las desigualdades espaciales al interior de las ciudades involucradas en pro del Centro Histórico intervenido, lo que propicia mayor presión en los usos del suelo, en sus residentes y en su composición económica-social. En tanto, las áreas periféricas se sumergen en el olvido con respecto a la dotación de equipamiento urbano y de reconfiguración del tejido social.

El movimiento, aunque nació desde la ciudadanía, los intereses, los obstáculos y la especificidad de las demandas han moldeado su destino. El movimiento ciudadano a favor de la protección del patrimonio cultural 
edificado entabló una lucha contra el Estado, como gestor de las regeneraciones urbanas y actividades económicas vinculadas, que lo obligaron a diluirse en la escena política. La conciencia social de la protección de un patrimonio colonial edificado fue debilitándose entre la cotidianidad, los acuerdos políticos y el desgaste. En tanto, los capitales inmobiliario y de entretenimiento siguen modificando el patrimonio según cambien los comportamientos del turista y los flujos de inversión.

El movimiento quizá nació como una lucha en contra de los embates del dominio hegemónico del capital en la cultura y las artes. Durante su recorrido ideó también que es posible que los ciudadanos puedan gozar de una vida plena en términos espirituales, sociales, culturales y políticos por el hecho de considerar que la apropiación del patrimonio material e inmaterial forma parte de su identidad e idiosincrasia; sin embargo, han sido las condiciones estructurantes y estructuradas (Bourdieu, 2003) las que delimitaron su destino hacia una específica manifestación transgresora. El reto es

persuadir a los productores culturales actuales de que reorienten su cólera hacia la mercantilización, la dominación del mercado y el sistema capitalista en general, ya que una cosa es ser transgresor con respecto a la sexualidad, religión, hábitos sociales y convenciones artísticas y arquitectónicas, y otra muy distinta serlo en relación con las instituciones y prácticas del dominio capitalista insertas hasta lo más hondo en la esfera cultural (Harvey, 2013:164). 


\section{Referencias}

Bourdieu, Pierre (2003), La distinción. Criterio y bases sociales del gusto, Ciudad de México, Taurus.

El Diario NTR (10 de octubre de 2014), «Rechazan obras en la Alameda», El Diario NTR.

Gobierno del estado de Zacatecas (1988-2012), Informes y anexos de gobierno, Zacatecas.

González, Cristo (2 de diciembre de 2013), «Por rehabilitación cierran calle García de la Cadena», El Diario NTR.

Harvey, David (2006), A produção capitalista do espaço, São Paulo, Annablume. (2011), Condição pós-moderna, São Paulo, Edições Loyola. (2013), Ciudades rebeldes. Del derecho a la ciudad a la revolución urbana, Madrid, Akal.

Instituto Nacional de Estadística, Geografía e Informática (INEGI) (1989, 1994, 1999, 2004 y 2009), Censos Económicos de Comercios y Servicios 1989, 1994, 1999, 2004 y 2009, Aguascalientes.

La Jornada Zacatecas (11 de noviembre de 2014), «Realiza ayuntamiento capitalino marchas exploratorias; regeneran la imagen urbana», La Jornada Zacatecas.

Ollaquindia, Raquel (15 de octubre de 2014), «Vecinos denuncian obras innecesarias en el proyecto de restauración para la Alameda», La Jornada Zacatecas. Ríos, Alma (28 de mayo de 2015), «Organización civil busca que Centro Histórico obtenga declaratoria como Zona de Monumentos», La Jornada Zacatecas. (31 de mayo de 2015a), «Organizarán foro de consulta ciudadana sobre políticas oficiales en materia cultural», La Jornada Zacatecas. 


\section{GENEALOGÍA DE LA MERCANTILIZACIÓN DEL PATRIMONIO CULTURAL}

Secretaría de Turismo (Sectur) (2012), Compendio estadístico del turismo en México 2012, Ciudad de México.

Torres, Antonio (7 de octubre de 2014), «Vecinos de la Alameda rechazan inicio de obras de remodelación», El Diario NTR. 